\title{
Media portrayal of psychosis in Sinhalese newspapers over two points (1986 and 2011) in time
}

\author{
P Wickrama
}

\section{Background}

Stigma affects patients with mental illness, their families and treatment providers. The way in which the media portray mental illness often propagates stigma. This area has not been studied in Sri Lanka.

Aims

To evaluate the coverage of mental illness (psychosis) in Sinhalese newspapers during two periods in time.

\section{Methods}

Relevant articles were identified using pre-identified search terms from two major daily Sinhalese newspapers published over 8 weeks in 1986 and 2011. Selected articles were categorised based on whether they were directly related to psychosis or used search terms as adjectives. The content of articles directly related to psychosis were analysed under six themes and rated for two key messages.

\section{Results}

Out of 180 articles identified, 99 were directly related to psychosis and 81 used the search terms as adjectives. There were only 9 medical news reports.
Of the directly related articles, $27 \%$ discussed the theme of psychotic patients being dangerous and $21 \%$ discussed the causation of illness, mostly highlighting the environmental factors. While $32 \%$ articles discussed treatment, biological forms of treatment were rarely discussed. The only difference between the two periods was the reduction of advocacy articles in 2011. A limited number of articles discussed prevention or the importance of an exact diagnosis. Only $15 \%$ of articles carried the message that mental illness is treatable, while $56 \%$ of articles portrayed mental health negatively.

\section{Conclusion}

There was no evidence of improvement in reporting of psychosis in Sinhalese newspapers over the last 25 years. Addressing this would help in reducing stigma associated with psychiatric illness.

Key words: Newspaper reporting, schizophrenia, Sri Lanka, stigma, mental illness

SL J Psychiatry 2016; 7(1): 9-14

\section{Introduction}

Schizophrenia is associated with significant stigma, which may lead to labelling, stereotyping, segregation and discrimination. An ever-increasing body of literature suggests that mental health literacy among public is meagre and that there is a close connection between this and stigma related to mental health (1). The media is a major source of information, which shapes public understanding of mental illness. Media reporting influences the policy decisions of a society (2). When the media portrays a group in a negative light, it is likely to propagate prejudice and discrimination against that group (3). Many authors have researched the depiction of mental illness by the media and the manner in which it contributes to stigma towards mental illness. Recent research on mental illness and the media indicates that research interest in this area, particularly with regards to newspaper reporting, is growing (4). While most of these studies considered mental illness in general (2-4), some studies have focused on specific illnesses such as schizophrenia and psychosis $(5,6)$. General findings suggest that newspapers report on mental illness or schizophrenia in a negative manner, using pejorative terms and associating mental illness with dangerousness $(5,7-9)$. The term schizophrenia is commonly used as a metaphor (9). When international data on news coverage during the two study periods were compared, the findings were mixed. While some studies reported an improvement of reporting across time - for example, depiction of causation using a biomedical model and highlighting of aspects such as recovery from illness - other studies failed to show such positive change $(2,11,12)$. There is no published data on depiction of schizophrenia or psychosis in Sri Lanka.

\section{Methods}

A descriptive study was done on Sinhalese newspaper articles on psychosis. Sinhalese newspapers were selected as they have the widest coverage in Sri Lanka. 'Dinamina' and 'Diwaina', the only two broadsheet daily Sinhalese newspapers with weekend editions which have been published continuously over the past twenty-five years, were selected for the study. Publications over a period of eight weeks in November/ December 2011 and 
publications over same period in 1986 were read to identify relevant articles (244 newspapers).

The notion of psychosis was chosen over schizophrenia as the Sinhalese term for schizophrenia (Bhinnonmadaya) was coined recently and the illness is not a popular concept in the language. Term 'psychosis' was defined as per Oxford dictionary: A severe mental disorder in which thought and emotions are so impaired that contact is lost with external reality. This definition was used for this study. Search terms corresponding to psychosis in the Sinhalese language were identified by referring to a pilot study done in 2006 (13), and by discussing with an expert in the Sinhalese language, after reading 25 newspapers. Colloquial terms as well as any term or institution directly related to treatment of psychosis were included in the search terms. The umbrella term “manasika roga” (mental illness) was also considered as denoting psychosis in the Sinhalese language. Selected newspapers were manually scanned for articles containing search terms. Selected articles were again discussed with the expert to exclude articles which used search terms not pertaining to psychosis.

The selected articles were categorised according to four criteria; date, newspaper, page of appearance and type.
Those reports were studied to see whether they were directly related to psychosis or used the term related to psychosis to describe another person or action. The latter was considered as adjective forms. The contents of articles directly related to psychosis were analysed and coded thematically by the main investigator. The themes were dangerousness, causation, treatment, advocacy, prevention and diagnosis. Finally articles that directly related to psychosis were rated by two trainees in psychiatry two key messages; mental illnesses are treatable and people with mental illness can lead worthwhile lives. These two raters were trained by the main investigator, using 25 articles, till the inter-coder reliability achieved a kappa value of 0.9 . The final intercoder reliability was 0.75 for the first message and 0.81 for second. Any discordant articles were rated by the main investigator.

Data was analysed using SPSS version 20. Ethical clearance was obtained from the ethics committee of General Hospital, Trincomalee.

\section{Results}

17 search terms were identified corresponding to psychosis in Sinhalese language (Table 1).

\begin{tabular}{|c|c|c|}
\hline The term & $\begin{array}{l}\text { Percentage of } \\
\text { articles using terms } \\
\text { in adjective form }\end{array}$ & $\begin{array}{l}\text { Percentage of articles } \\
\text { using terms directly } \\
\text { related to psychosis }\end{array}$ \\
\hline 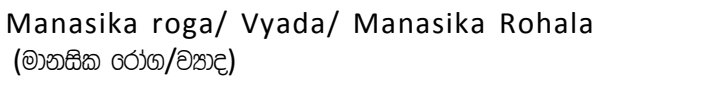 & $02.85 \%$ & $42.22 \%$ \\
\hline 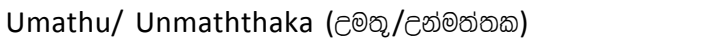 & $17.14 \%$ & $17.77 \%$ \\
\hline 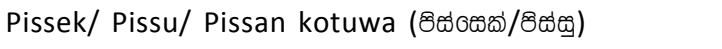 & $64.76 \%$ & $16.66 \%$ \\
\hline 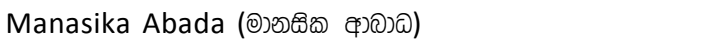 & $01.90 \%$ & $07.77 \%$ \\
\hline 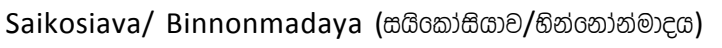 & - & $04.44 \%$ \\
\hline 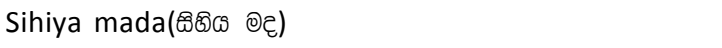 & - & $03.33 \%$ \\
\hline Sihiya wikal (ఱిఠిద రిळతి) & $03.80 \%$ & $02.22 \%$ \\
\hline Viyaru (อิબठఒ) & $02.85 \%$ & - \\
\hline Vikara (రిథ)ర) & - & $01.11 \%$ \\
\hline 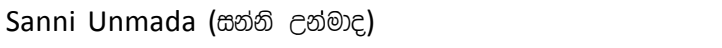 & - & $01.11 \%$ \\
\hline Olmada (ஹહ่ఠ)ટ̨) & $01.90 \%$ & $01.11 \%$ \\
\hline 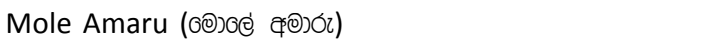 & $00.95 \%$ & $01.11 \%$ \\
\hline 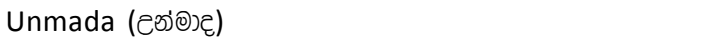 & - & $01.11 \%$ \\
\hline 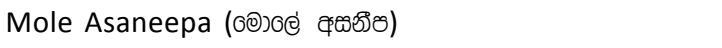 & $00.95 \%$ & - \\
\hline Maniawa (๑లิริตฺอ) & $00.95 \%$ & - \\
\hline Oluwa Awul (@®อ ๔อతి) & $00.95 \%$ & - \\
\hline Oluwa Upset (@@ల ๔రో6ణర) & $00.95 \%$ & - \\
\hline
\end{tabular}


Based on the search terms. 217 articles were identified in the two newspapers over the study period. Out of these, 27 articles were excluded as the term was not used in relation mental illness; for example: "Oya Rassawen

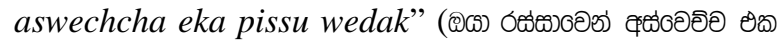

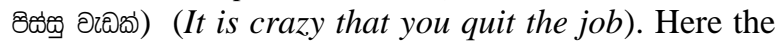
term "pissu" (ठ̊ळ@ - crazy) is used with a meaning of irrationality, not psychosis. In 180 articles the term was used to indicate illness and these were included in the study. Of these, 99 articles were directly related to psychosis and in 81 articles the terms were used as adjectives or adverbs (Figure 1 ).

In 81 articles the search terms were used as adjectives. For example: "Iye ohu usaviyedi pisseku wage

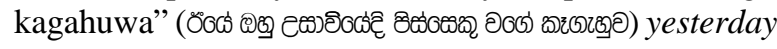
he shouted in the courts like a lunatic). Here the term "pisseku” (శळంఱळ్-lunatic), a term meaning psychosis, is used as an adverb and is considered as adjective use. This is in contrast to "Iye usawiyedi pisseku kagahuwa"

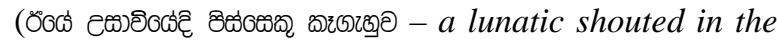
courts yesterday) where the term directly describes the action of a person with psychosis.

Adjective forms appeared in 34 articles in 1986 (0.28 per paper) and 47 articles in 2011 (0.38 per paper). There was no significant difference in the numbers of articles in adjective forms between years or between two papers. The most frequently used term in adjective form was the colloquial term "pissesk" (65\%) followed by the term "unmaththaka” (17\%) (Table 1). This adjective use mostly appeared in fiction ( $\mathrm{n}=27)$ followed by opinions/ letters to editor $(n=18)$, general news reports $(n=13)$, biographies $(n=12)$ and editorials $(n=3)$. The adjective forms almost always conveyed a negative meaning mostly irrationality or dangerousness.

In 99 articles the search terms were directly related to psychosis, 56 in the year 1986 (0.46 articles per paper) and 43 in 2011 ( 0.35 per paper). There was no significant difference between the numbers of selected articles per paper between the two years. Articles were mostly general news reports $(n=36)$ followed by opinions or letters to the editor $(n=20)$, legal reports $(n=13)$, fiction $(n=10)$ and editorials $(n=3)$. One editorial discussed the inadequacy of mental health services of the country, another discussed a homicide at the mental hospital, Angoda and third highlighted ragging in universities, claiming that offenders were suffering from psychosis. There were 9 health reports explaining the illness, 4 of them giving ayurvedic explanations. Only 5 carried the opinion of a psychiatrist/ western health professional and all of these were regarding advocacy aspects and none provided explanations regarding psychiatric illness.

The most commonly used term was "Manasika Roga" followed by "Umathu/ Unmaththaka”. These terms were used pejoratively or colloquially in $17 \%$. Only 4 articles carried the direct translated terms for schizophrenia or psychosis (Table 1).

Table 2 describes the themes and sub themes of the articles directly related to psychosis. As a single article may contain more than one theme or sub themes the total number do not tally.

Total number of articles with a search term $(n=217)$

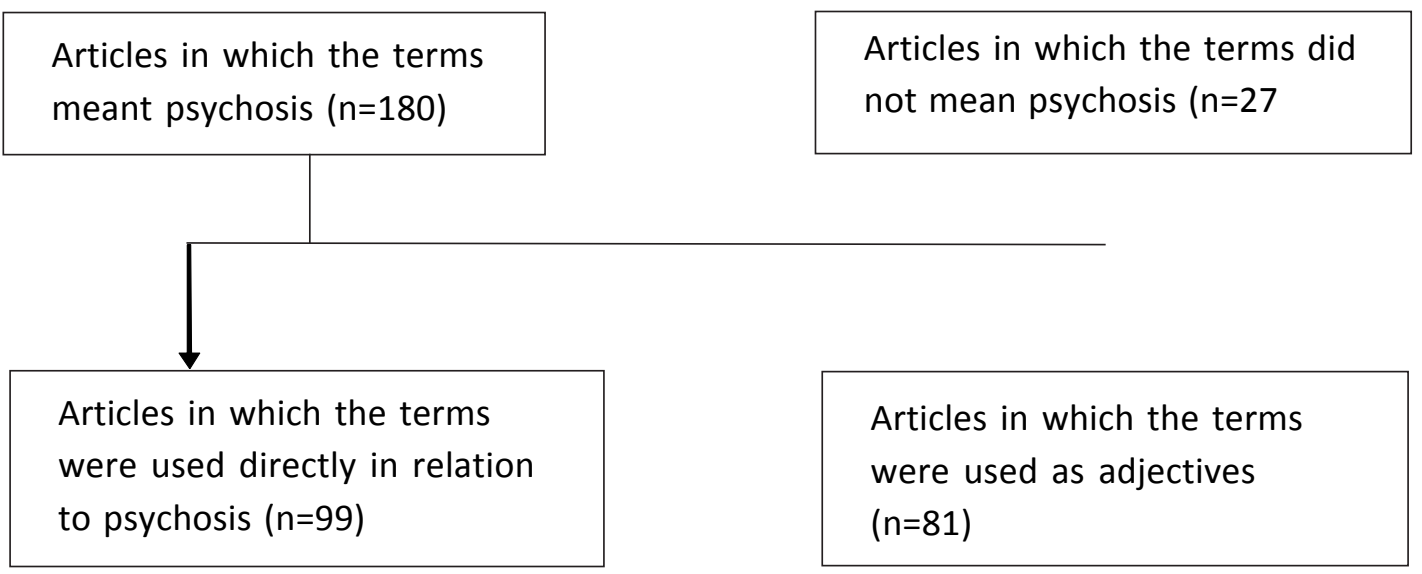

Figure 1. Flow diagram showing article selection process used in this study. 
Table 2. Themes and sub themes of the articles directly related to psychosis, which appeared in two Sinhalese newspapers over the study period, with the number of articles

\begin{tabular}{|c|c|c|c|}
\hline Themes and subthemes & 1986 & 2011 & Total \\
\hline Dangerousness & $28(25.6 \%)$ & $16(30.8 \%)$ & $44(27.3 \%)$ \\
\hline Crime against others & 20 & 10 & 30 \\
\hline Being a victim of a crime & 10 & 03 & 13 \\
\hline Self-harm & 05 & 04 & 09 \\
\hline Involve in legal procedure & 05 & 03 & 08 \\
\hline Drug/ alcohol abuse & 01 & 03 & 04 \\
\hline Non-violent crime & 02 & 02 & 04 \\
\hline Causative factors & $20(18.3 \%)$ & $14(26.9 \%)$ & $34(21.1 \%)$ \\
\hline Environmental causes & 10 & 08 & 18 \\
\hline Life stress & 04 & 02 & 06 \\
\hline Super natural causes/planets/fate & 02 & 03 & 05 \\
\hline Drug and alcohol & 04 & 01 & 05 \\
\hline Biological & 03 & 00 & 03 \\
\hline Ayurvedic explanation & 01 & 01 & 02 \\
\hline Treatment & $33(30.3 \%)$ & $19(36.5 \%)$ & $52(32.3 \%)$ \\
\hline Angoda / Mulleriyawa Hospital & 21 & 03 & 24 \\
\hline Psychiatrists & 09 & 08 & 17 \\
\hline Psychiatry units & 06 & 03 & 09 \\
\hline Medication & 03 & 02 & 05 \\
\hline Ayurvedic treatment & 03 & 02 & 05 \\
\hline Rituals & 02 & 01 & 03 \\
\hline Community treatment & 02 & 01 & 03 \\
\hline Psychologist/psychotherapist & 02 & 00 & 02 \\
\hline Occupational therapy & 02 & 00 & 02 \\
\hline ECT & 00 & 01 & 01 \\
\hline Hypnotherapy & 00 & 01 & 01 \\
\hline Advocacy aspects & $21(19.3 \%)$ & 01 (1.9\%) & $22(13.6 \%)$ \\
\hline Lack of psychiatrists & 06 & 00 & 06 \\
\hline Short comings at NIMH & 05 & 00 & 05 \\
\hline Lack of psychiatry units & 05 & 00 & 05 \\
\hline Lack of other staff & 04 & 01 & 04 \\
\hline Other & 02 & 00 & 02 \\
\hline Prevention aspects & $04(3.6 \%)$ & 01 (1.9\%) & 05 (3.1\%) \\
\hline Community interventions & 02 & 01 & 03 \\
\hline Better life style & 01 & 00 & 01 \\
\hline Early diagnosis & 01 & 00 & 01 \\
\hline Specific diagnosis & $03(2.7 \%)$ & 01 (1.9\%) & $04(2.5 \%)$ \\
\hline Schizophrenia & 02 & 01 & 03 \\
\hline Psychosis & 01 & 00 & 01 \\
\hline
\end{tabular}

The most commonly seen themes were treatment and dangerousness. Aspects of prevention or specific diagnoses were discussed only rarely. Except for the higher number articles regarding advocacy in 1986 ( $p<0.01$, Fisher's exact test) there was no significant difference in other categories of articles across the years.

When the articles were analysed for specific messages regarding treatability of illness, $15 \%$ indicated that psychosis is treatable, another $15 \%$ were negative and the remainder of articles did not carry any message regarding this aspect, and there was no difference in the between the two periods studied. Only 5 articles gave a positive message regarding people with psychosis - for instance, that they can lead a productive life - whereas 56 articles were negative. Again, there was no significant difference between the two study periods in this regard.

In many instances the headings of newspaper articles linked dangerousness to psychosis. Three such were

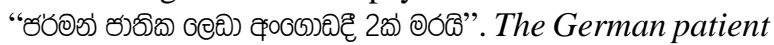
kills two at Angoda psychiatric hospital 1986 \&, - 


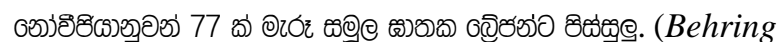
who killed 77 Novigeons is said to be psychotic 2011)

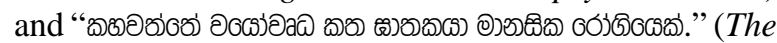
person who killed an elderly woman at Kahawattha is mentally ill 2011). In an interview with a government minister regarding the shooting and murder of a

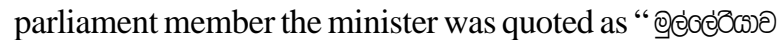

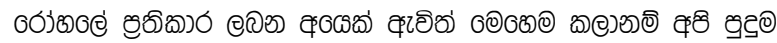

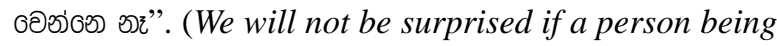
treated at a psychiatric hospital did this murder 2011) again attaching dangerousness to illness.

\section{Discussion}

Many of the search terms used in this study have been long established in the Sinhalese language, including usage in early Sinhalese literature. However the findings of this study suggest that in recent times, some of these terms are being misused with a derogatory meaning, and without clear relevance to the illness.

Actual Sinhalese terms for psychosis or schizophrenia appeared in only 4 articles (one article per 60 papers). A significant number (45\%) used terms corresponding to psychosis as adjectives. Almost always adjectival usage conveyed a negative meaning, which was mostly irrationality or dangerousness. This is a matter of significant concern, especially since, according to the social cognitive theory, newspaper reporting has a harmful effect on public perception of mental illness (14).

One significant finding was the lack of accurate medical reports imparting true knowledge about psychosis and the absence of professional opinions in reporting, which is in contrast to international findings. Out of 450 articles related to mental health issues identified from six daily newspapers and weekly periodicals from Croatia, Slovakia and the Czech Republic, the opinion of a mental health professional was sought in one-third of published articles (8). This finding in our study may reflect a shortcoming on the part of psychiatrists in addressing the general Sinhalese society through the major newspapers. Alternatively it may reflect a reporting bias within media organisations, with neglect of dissemination scientific knowledge on mental illness.

Many articles implied an association between dangerousness and people with psychosis. It is possible to consider whether crimes done by a person with psychosis is reported more often, compared to crimes committed by healthy persons, although this was not researched in this study. It is rare for a person with a mental illness to commit a crime, when confounders like substance abuse are excluded. They are more likely to be a victim of a crime, which was not reflected in the Sinhalese newspapers. Our findings are similar to research from United States (15), South Korea (6), the United Kingdom (12) and Central Europe (8). Unlike in Sri Lanka, in recent years these trends have improved in the United States and United Kingdom, with these positive changes being ascribed to extensive public awareness campaigns, stigma reduction campaigns, awards and guidelines for better media coverage and an active relationship between psychiatrists and the media.

Most articles in this study discussed environmental causes for psychosis (46\%) and few articles discussed biological causes (7\%). In the United Kingdom 22\% articles discussed biological aspects in aetiology or treatment (12). Although past research has suggested that in Asian cultures people commonly believe symptoms of mental illness to be due to supernatural causes (16), this hypothesis was not reported in newspapers in our study.

A significant number of articles discussed treatment, mostly in relation to the National Institute of Mental Health Sri Lanka. This prominence was markedly reduced in 2011. Positive developments at NIMH were not covered in the scrutinized newspapers. Biological treatments were rarely mentioned. This may be due to low mental health literacy, stigma towards biological treatment or lack of medical articles. This is in contrast to studies done elsewhere, in which over $85 \%$ of the newspaper articles about psychiatry discussed treatment options (17).

A wide variety of advocacy aspects, including shortcomings at NIMH, lack of mental health units, lack of psychiatrists and other staff were discussed in 1986 but was not noted in 2011.

Given these findings, on one hand it appears prudent to popularise specific names for psychosis or schizophrenia in the Sinhalese language. However whether this will lead to less discrimination is debatable. Chung et al., (18) in China investigated whether a less pejorative name for schizophrenia could reduce stigma, and found that this did not have a significant effect on measures of attitude. Rather than a change of terms, the manner in which these terms or names are used is likely to have a more definite impact on reducing stigma.

As highlighted by Thornicroft et al., stigma consists of ignorance, prejudice and discrimination (19). The negativity of the messages conveyed in the Sinhalese newspapers echoes this concept.

\section{Limitations}

Only two Sinhalese newspapers were selected, thus omitting a large number of other newspapers and magazines that reach the public, which may have biased the findings of this study. The period of assessment included only two months during the selected years. This may not be sufficient to identify a trend in reporting. Terms corresponding to psychosis in the Sinhalese language were selected subjectively. This may have led to over or under representations of terms. For example the term "manasikaroga" is an umbrella term and may not always mean psychosis. Coding and content analysis was done by the author only, leading to lower reliability of results compared the use of several raters. 


\section{Conclusions}

There was no significant change or improvement in reporting on mental illness in the Sinhalese newspaper media, over the last 25 years. This is a key concern, since negative media reporting will continue to hinder development of mental health services, and adversely influence public perception of mental illness. This is an issue that should be addressed urgently, and psychiatrists in Sri Lanka should also establish good collaboration with the media, in order to provide scientific and accurate information to the public.

\section{Acknowledgements}

I would like to thank Dr Jayan Mendis, Dr Sandagomi Coperahewa and staff of National Library of Sri Lanka.

\section{Conflicts of interest}

None declared

\author{
P Wickrama, Base Hospital, Chilaw \\ Corresponding author: $\mathrm{P}$ Wickrama \\ Email: prabathwickrama@gmail.com
}

\section{References}

1. Crisp A, Gelder MG, Goddard D, et al. Stigmatization of people with mental illness: a follow-up study within the changing minds campaign of the Royal College of Psychiatrists. World Psychiatry 2005; 4: 106-13.

2. Paterson B. Newspaper representations of mental illness and the impact of the reporting of 'events' on social policy: the 'framing' of Isabel Schwarz and Jonathan Zito. Journal of Psychiatric and Mental Health Nursing 2006; 13: 294-300.

3. Corrigan PW, Watson AC, Gracia G, Slopen N. Newspaper Stories As Measure of Structural Stigma. Psychiatr Serv 2005; 56(5): 551-6.

4. Stout PA, ViUegas J, Jennings NA. Imagesof Mental Illness in the Media: Identifying Gaps in the Research. Schizophr Bull. 2004; 30(3): 543-61.

5. Dubugras MTB, Evans-Lacko S, Mari JJ. A Two-Year Cross-Sectional Study on the Information about
Schizophrenia Divulged by a Prestigious Daily Newspaper. The J Nerv Ment Dis 2011; 199(9): 659-65.

6. Park JH, Choi YM, Kim B, Lee DW, Gim MS. Use of the Terms "Schizophrenia" and "Schizophrenic" in the South Korean News Media: A Content Analysis of Newspapers and News Programs in the Last 10 Years. Psychiatry Investigation 2012; 9: 17-24.

7. Wahl OF. Mass Media Images of Mental Illness. A Review of the Literature. Journal of Community Psychology 1992; 20: 343-52.

8. Nawkova L, Nawka A, Adamkova T, et al. The picture of mental health/illness in the printed media in three Central European countries. J Health Commun 2012; 17(1): 22-40.

9. Coverdale J, Nairn R, Claasen D. Depictions of mental illness in print media: a prospective national sample. Aust N Z J Psychiatry 2002; 36: 697-700.

10. Duckworth K, Halpern JH, Schutt RK, Gillespie C. Use of Schizophrenia as a Metaphor in U.S. Newspapers. Psychiatri Serv 2003; 54(10) : 1402-04.

11. Francis C, Pirkis J, Blood R W, et al. The portrayal of mental health and illness in Australian non-fiction media. Aust N Z J Psychiatry 2004; 38: 541-6.

12. Goulden R, Corkern E, Evans-Lacko S, Rose D, Thornicroft G, Henderson C. Newspaper coverage of mental illness in the UK, 1992-2008. BMC Public Health 2011; 11: 796.

13. Mendis BJ, Wickrama PB, Suthakaran S, Fernando WDD. How mental health related topics are covered in Sri Lankan newspapers? 8th Annual academic sessions of Sri Lanka College of Psychiatrists 2008; Mar 10-13; Colombo.

14. Blood RW, Pirkis J. Suicide and the media part III: theoretical issues. Crisis 2001; 22 (4): 163-9.

15. Vahabzadeh A, Wittenauer J, Carr E. Stigma, schizophrenia and the media: exploring changes in the reporting of schizophrenia in major U.S. newspapers. J Psychiatr Pract 2011; 17( 6): 439-46.

16. Lauber C, Rossler W. Stigma towards people with mental illness in developing countries in Asia. Int Rev Psychiatry 2007; 19(2): 157-78.

17. Stuber J, Achterman P. Washington state newspaper coverage of mental health issues. Seattle, WA: University of Washington; 2009.

18. Chung KF, Chan JH. Can a less pejorative Chinese translation for schizophrenia reduce stigma? A study of adolescents' attitudes toward people with schizophrenia. Psychiatry Clin Neurosci 2004; 58(5): 507-15.

19. Thornicroft G, Rose D, Kassam A, Sartorius N. Stigma: ignorance, prejudice or discrimination? Br J Psychiatry 2007; 190: 192-93. 